\title{
Directed and Emergent Play
}

\author{
Brigid M Costello \\ School of English Media \& Performing Arts \\ University of New South Wales Sydney, \\ NSW, Australia bm.costello@unsw.edu.au
}

\author{
Ernest A Edmonds Creativity and \\ Cognition Studios University of \\ Technology, Sydney Sydney, \\ NSW, Australia \\ ernest@ernestedmonds.com
}

\begin{abstract}
We describe a case study of the audience experience of an interactive artwork titled Just a Bit of Spin. This study was part of practice-based research project that aimed to develop strategies for designing for a play experience. In this paper, we focus on results relating to the two play characteristics of difficulty and competition. These results lead us to reflect on the importance of creating a balance between directing the play experience and providing opportunities for play to emerge through the creative activities of the player.
\end{abstract}

\section{Author Keywords}

Play, interaction design, user experience, human-computer interaction, practice-based research, interactive art.

\section{ACM Classification Keywords}

H.5.2. [Information Interfaces and Presentation]: User Interfaces---Evaluation/Methodology, Input Devices and Strategies, Screen Design. J.5 [Computer Applications]: Arts and Humanities--- Fine arts.

\section{General Terms \\ Design, Human Factors.}

\section{INTRODUCTION}

This paper discusses results from an artist-led practicebased research project that has investigated play as a strategy for encouraging audience engagement with interactive artworks. The project developed a framework of the characteristics of a play experience and this framework was used as a tool during the design and evaluation of two iterations of an artwork called Just a Bit of Spin. In this paper we will focus on the second iteration of Just a Bit of Spin and on our aim to stimulate playful audience responses by increasing the complexity of the artwork's structure both in terms of its interactions and its content. This design aim was a response to the results from an audience evaluation of the first iteration of the work, which had indicated that in order to stimulate play the work needed to provide more opportunities for the audience to creatively explore its possibilities. The paper will first describe the influence that this aim had over the design of the second iteration and then outline the results of a subsequent audience evaluation. These results have lead to a greater understanding of the creative relationship between a playful work and its player. They have also caused us to reflect on the balance between those aspects of the work directed by the artist and those that can emerge from the relationship between the artwork and the audience.

\section{BACKGROUND}

A key design issue for many interactive artists is the problem of quickly engaging an audience member with an unfamiliar interactive system. An audience member needs to work out what type of participation is possible before he or she can begin to engage with a system and there may be several possibilities to explore. The danger is that an audience member will never move from this working out phase into any type of engagement with the work. The artwork will therefore have little meaning for them.

This project began with the hypothesis that play could be one way to quickly engage an audience member with an artwork and lead him or her to explore the work fully. Play was chosen as an approach because it is an experience that involves exploration and engagement. Based on this hypothesis the project aimed through the creation and evaluation of interactive works to develop some practical design strategies for stimulating a play experience. Although the project took place within an interactive art context it was, therefore, more focused on the design aspects of the creation process and their effect on audience experience than on specific art outcomes.

In common with recent user experience research from the HCI community this project took the position that an experience is not something that can ever be precisely controlled by a design. Experience is something one can design for rather than something one designs in [13]. This attitude recognises the variable nature of the user and respects the important effect that this variability can have on the dynamics and resulting character of an interactive experience. Conclusions from the study are, therefore, seen as open-ended strategies and understandings rather than as formulas or recipes for creating a specific effect. 
As a starting point, this project used Salen and Zimmerman's very broad definition of play as "free movement within a more rigid structure" [11], because this broad definition seemed to suit the equally broad possibilities that the interactive art context provided. The project then synthesised six existing theories about the characteristics of play to arrive at a framework of thirteen characteristics that could define a playful interactive art experience. These characteristics were: creation, exploration, discovery, difficulty, competition, danger, captivation, sensation, sympathy, fantasy, simulation, camaraderie and subversion. These thirteen characteristics and the theories that contributed to the play framework have been described in previous publications [2, 3].

In this paper we are focusing particularly on the characteristics of difficulty and competition. Difficulty is used to refer to the pleasure one might experience when during play one has to develop a skill or to exercise skill in order to do something. Competition is used to refer to the pleasure one might experience when trying to achieve a defined goal. In practice both these characteristics are often linked. For example, a person might need to develop or exercise a skill in order to achieve a goal. Similarly, a person might define several goals during the process of developing a skill. These two characteristics, difficulty and competition, are sub-categories of the pleasure of being a cause, a pleasure that Groos regards as the overarching pleasure of all play experiences [4]. This pleasure is one of the commonly noted parallels between play and creativity.

A common feature of many discussions of play is the identification of two types of practices, one involving interpretation of the structure that play occurs within and the other involving making some change to this structure. Salen and Zimmerman, for example, draw attention to the two practices of meaningful play and transformative play. Their concept of meaningful play draws on Huizinga's definition of play, particularly on his statement that "[all] play means something" [6]. Meaningful play is what occurs when a player's interactive "actions and outcomes" are "integrated" into the wider context of the work [11]. Salen and Zimmerman describe meaningful play as something that a game designer needs to design into the structure of their game and regard it as an essential element for a game to be successful. Transformative play, on the other hand, while not regarded as essential for success within a game, is regarded as operating to make a game more exciting because it transforms or changes the "rigid structure" that the game takes place within [11]. Their concept of transformative play describes activities such as digital game modification or any other play that blurs the boundary between a game system designer and a player. Transformative play, then, involves practices that are structurally creative while meaningful play involves practices that are structurally interpretive.
Other studies of play behaviour have also focused on two practices at work within play, although these studies do not focus on transformation or meaning but rather on exploration [7, 8]. Hutt describes the two types of exploration that children undertake when playing with a novel object as "investigative exploration" and "diversive exploration" [7]. Investigative exploration occurs, she says, when children have the goal of "getting to know the properties" of the object. Once they have done this they then shift into diversive exploration and this involves a change of emphasis "from the question of "what does this object do?' to 'what can I do with this object?'” [7]. For Hutt and others, play only occurs when children are engaged in diversive exploration but, they stress, this will not occur until there is some level of familiarity with an object, and this is attained through investigative exploration. These two processes are often intertwined, with children moving from investigating to playing and then back to investigating when they uncover a new feature or if they become bored.

In these terms designing for a play experience, therefore, requires not just considering the issue of maintaining player interest in the diversity of "what they can do" it also potentially involves managing their unfolding investigation of "what this object does". To stimulate this investigation, Lieberman says, we need to work with "novelty, ambiguity, incongruity, surprise, and complexity". On the other hand, to stimulate the diversive exploration of play we need to work with "familiarity, clarity, simplicity, and congruity"(1977: 109). These two lists might appear at first to be incompatible but it is important to remember that the first becomes the second through the process of player exploration.

Another theorist who identifies two practices within play is Callois who makes a distinction between paidia, the "primary power of improvisation and joy", and that of ludus, "the taste for gratuitous difficulty". In his broader definition of paidia he uses the words "gamboling", "happy exuberance" and "tumult" to further describe its character [1]. Caillois links ludus to the "acquisition of a special skill", to "mastery" and to "the primitive desire to find diversion and amusement in arbitrary, perpetually recurrent obstacles" [1]. He sees these terms as operating at the two ends of an axis that can then be used categorise types of play. Ludus is used to describe more ruled, skilled-based play and paida more improvisational free-form play.

A common feature of discussions of play is, then, an identification of two modes of practice that a play experience can oscillate between. Here we have seen theorists describe continuums between meaningfulness and transformation; between investigation and the exploration of diversity; and between ruled, skill-based play and freeform, improvisational play. Although these continuums each have a different experiential focus, a common feature is that one side involves working with or interpreting a 
defined structure and the other involves being creative with or within this structure. What we are seeing here, then, echoes the definition of play as "free movement within a more rigid structure" but relates it to the practices of the player, which oscillate between "what can this object do?" (rigid structure) and "what can I do with this object?" (free movement). These two modes of practice became a particular focus of this project when it was revealed that the first iteration of Just a Bit of Spin frequently caused its audience to focus more on what the artwork could do than on what they could do with it.

\section{THE FIRST ITERATION OF JUST A BIT OF SPIN}

Just a Bit of Spin is an interactive artwork that uses phrases taken from the speeches of Australian politicians to comment on the meaninglessness of modern day political language. The interface is a reworking of an early animation device called a phenakistoscope. Spinning the disk in Just a Bit of Spin not only creates an animation but also produces sounds, and the speed of the disk controls the speed of these sound files. If the disk is spun first in one direction and then in the other, a bit like a DJ scratching a record, the phrases within the work are mixed up.

The first iteration of Just a Bit of Spin was a working prototype constructed quite cheaply out of cardboard, broomsticks and wire (figure 1). The phrases within this version of the work all contained either the word forwards or the word backwards. When the disc was spun to the right the forwards phrases would play. When the disc was spun to the left the backwards phrases would play. The cardboard disk had a circular graphic image on its rear surface and this image was reflected back in a mirror. This graphic image represented the then current Australian Prime Minister running in two directions and these figures would animate when viewed through the spinning slits of the wheel.

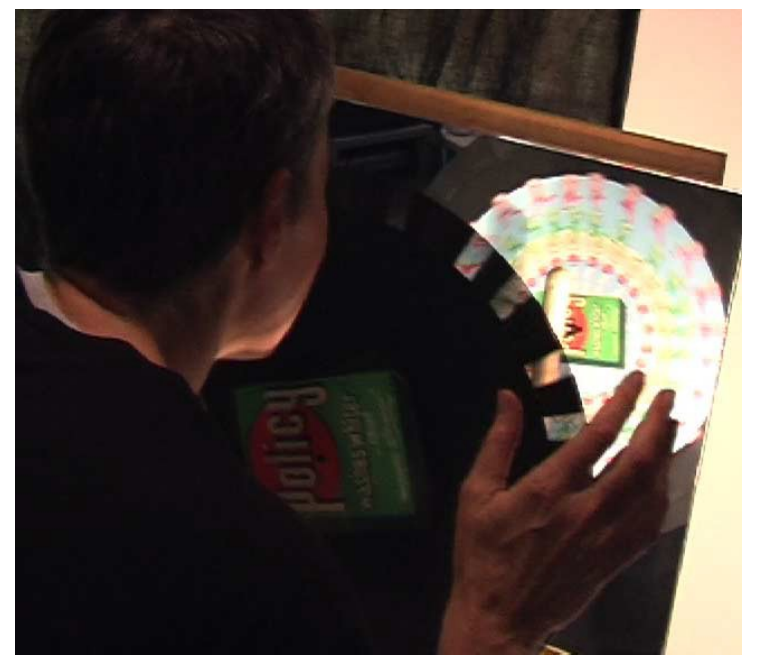

Figure 1: Person interacting with prototype

The audience experience of the prototype of Just a Bit of Spin was evaluated along with two other artworks (see [3]).
This evaluation revealed that, of the three artworks, Just A Bit of Spin was the work that least made many of the participants play. There was a feeling that Just a Bit of Spin was a "blunter instrument" that "made its point fairly quickly" and once a participant had worked that out he or she "really didn't think there was much else there". As one participant comment indicated, this made the experience of this work more about exploring than playing:

The wheel was more about investigating and making sure that I'd covered its possibilities.

Once participants had covered these possibilities there did not seem to be enough to do in Just a Bit of Spin to then make them shift to playing. The other two artworks in contrast were works that you "could keep on playing with... and keep on figuring out or having an interest in". This seemed to be because these other artworks were much more technologically and conceptually mysterious for participants than Just a Bit of Spin. Many participants finished their experience of these other two works without feeling completely sure that they had understood them. Just a Bit of Spin, on the other hand, was regarded as easy to understand and as a work that had less creative possibilities. As one participant said "I couldn't change it as much as I would possibly be able to change the other ones."

In deciding how to translate these results into design directions for the next iteration of this work we again considered the definition of play as "free movement within a more rigid structure" [11]. We decided that the lack of possibilities described above was connected to not having enough freedom of movement. The openness and the puzzling interface of the other two artworks had a sense of movement that gave people something to play with. The Just a Bit of Spin prototype, on the other hand, was regarded as easy to understand both as an interface and as a piece of communication and this gave it a finiteness that worked against play. Increasing the potential of this work to stimulate play would, therefore, involve working to increase the freedom of movement within its structure.

\section{THE SECOND ITERATION OF JUST A BIT OF SPIN}

The design of the second iteration of Just a Bit of Spin aimed to provide more freedom of movement by increasing the work's complexity both in terms of its structure and its content. It also aimed to do so in a way that would give people a sense that they were able to have more of an effect on the work. The immediate approach to this involved coming up with more paired word combinations similar to the forwards/backwards pair used in the prototype. These word pairs were used to create a more complex structure within the work and were combined with deliberately ambiguous imagery to create more complex content for the audience to interpret.

Each pair of words was an opposition: forwards/backwards, hard/soft and something/nothing. The artist had noticed, when editing the phrases, that politicians used these words 
to push a particular meta-level meaning: forwards/backwards was about the importance of progress, hard/soft was about not being weak and emotional and something/nothing was about giving the impression that action was being taken while at the same time avoiding saying anything specific.

This new artwork structure would have these paired words occurring on three separate levels so that there was now a progression of things to uncover within the artwork. This was because during the first evaluation puzzling things out tended to shape the length of people's experiences. They often stopped interacting after they had solved some puzzle and this lead to the conclusion that designing a puzzle-like thread into an artwork could work to maintain people's engagement. For this artwork that thread would be finding the three levels. The mechanism to move people between these levels would be one of the interactions that had caused the most playful behaviour. This was the scratching or mixing interaction that occurred when people moved the wheel back and forth quickly.

Each of the three levels was accompanied by a different set of animations and the graphics for these were inspired by the fruit images on old poker machines (figure 2). Although these animations were each connected to the meta-level meanings expressed by the phrases they were also deliberately designed to be ambiguous. Through this ambiguity the artist hoped to open up the possibility of interpretive play and provide room for more personal interpretations. This second iteration of Just a Bit of Spin would be exhibited in a public exhibition space and this meant that the wheel had to be much more robust and housed within a tamper-proof case (figure 3).

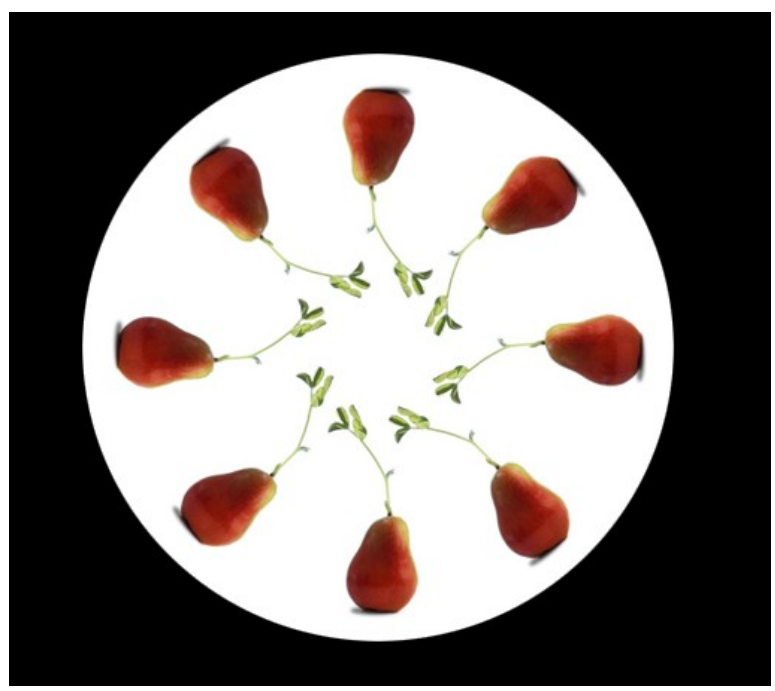

Figure 2: Example screen from second iteration

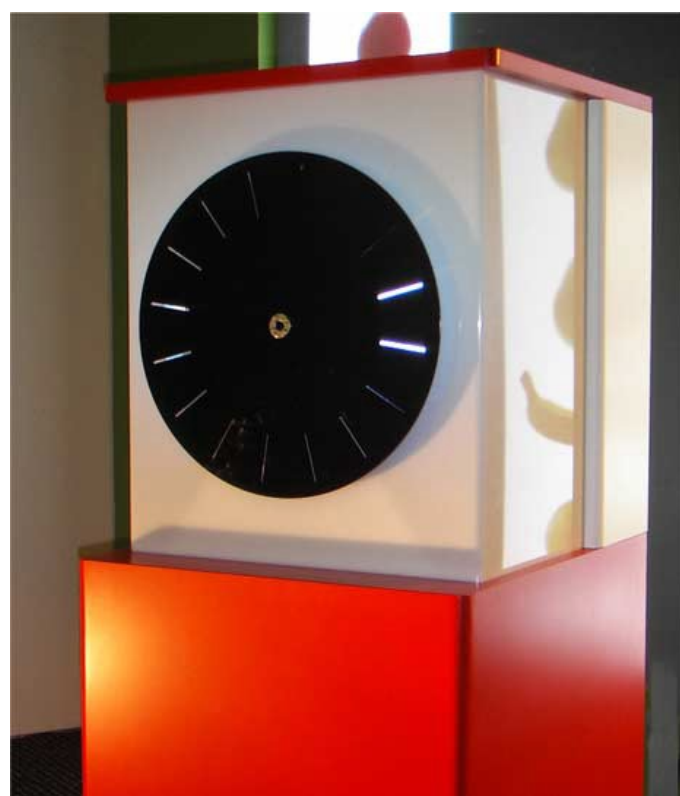

Figure 3: Case and wheel of second iteration

\section{CASE STUDY METHODS}

Between November 2007 and February 2008 this second iteration of Just a Bit of Spin was exhibited at the Powerhouse Museum in Sydney, Australia. During this time a case study of the artwork was conducted that aimed to reveal whether the redesign of the artwork had resulted in the type of experiences that were intended, particularly in terms of stimulating playful behaviours. The data collection for this case study occurred over a four-week period. This extended period involved three phases of data collection. The process began with four days of evaluations followed by three days of observation of museum visitors and, lastly, a final two days of evaluations.

\section{The Installation}

Just a Bit of Spin was installed within the Cyberworlds exhibition at the Powerhouse Museum. This is an exhibition that tells the history of computer technology from its earliest days to the present. For this installation the Just $a$ Bit of Spin case was placed central to and directly in front of a rear projection screen. It was positioned about a metre and a half away from the screen so that people walking past the space would get a glimpse of it and hopefully be enticed to enter. A series of slides containing poker machine-like strips of fruit were projected onto the large screen behind the case. These colourful slides rotated every 30-60 seconds and were another device that was designed to attract people into the space. The projected slides provided the lighting for the rear and sides of the case. The front of the case was left dark apart from a spotlight on the carpet where visitors would stand to interact. The only other lights in the space were two small spotlights on the exhibit posters.

It was always intended that the results from this case study of Just a bit of Spin would be compared with the earlier 
case study of the prototype version. In order to facilitate this comparison, the methods of data collection for this second case study remained similar to those used in the first study (see [3]) and seven of the first study's participants also took part in this study. There were, however, some necessary changes made to the methods used due to the different contexts involved. There were also some changes made that arose from the conclusions of the first study, changes that aimed to improve the methods used.

\section{The Observations}

Three separate covert observation sessions were conducted of approximately two to two and a half hours each. Two of these sessions were on a weekend and one was on a weekday. All were conducted during the middle part of the day, as this was the busiest time in the museum. The experiences of all people who entered the installation space during the three days of observation sessions were noted. The researcher was positioned just outside the exhibition space in a place where it was possible to see inside the room but where she was not obvious to the people who were interacting. Data was collected on an observation sheet, noting the length of each experience, the number, age and gender of the people involved, how many and which aspects of the work were uncovered, whether the participants laughed, whether they read the sign and whether they played with slowing the wheel down. The researcher also made general notes about anything else of interest, for example, notes about the social dynamics of the group or of particular behaviours such as people dancing. In total there were thirty experiences observed, roughly ten per session. Twelve of these experiences involved individuals. Of the other eighteen experiences, twelve involved pairs and six involved groups of three or more people.

\section{The Evaluations}

The structured evaluation sessions involved fifteen experiences in total. Of these, seven experiences involved a pair of participants and eight were individual. This made a total of twenty-two participants. Half of these participants were female. Ten were aged under 35 years old and twelve over, with the youngest being 20 years old and the oldest 48 years old. Ten of these participants were recruited from the general public of the museum on the day of their evaluation. All of the visitors who agreed to take part were at the museum with a social partner and experienced the artwork in a pair. The ten participants of this group, therefore, equate to five evaluation sessions. The other twelve participants were invited to take part. Eight of the invited participants were classed as expert because they were experienced in the creation of interactive or audiovisual works. Seven of the invited participants were classed as repeat participants because they had taken part in the earlier case study of the prototype for this work. The invited participants mainly experienced the artwork as individuals. There were two paired experiences and eight individual, making a total of ten evaluation sessions with invited participants.

Prior to an evaluation, each participant signed a research consent form. The evaluation session then had four phases. First the participants were given instructions to enter the space, to interact with the artwork as if they were interacting with any other exhibit in the museum and to leave whenever they felt they had had enough. They were also told that they would be interviewed about their experience afterwards. They then entered the space and were recorded on video and audio. The video camera was positioned to one side of the artwork so that it could capture any interactions with the wheel and also capture the participants when they were reading the poster. When participants were at the artwork, the camera took in their body from the waist up and captured the expressions on the faces of participants as well as their interactions with the wheel. Participants were on their own while they were interacting with the artwork. There was no camera operator and the entry to the installation space was screened off to stop anyone else from entering. Any comments that participants made were recorded on a small MP3 recorder that hung on a cord around their neck.

The second phase of the evaluation involved a structured interview with twelve questions. This involved one set of questions designed to encourage participants to express their experiences in different ways, such as, by explaining the work to a friend, describing their mood, or summarising their experience in three words. Another set of questions focused on participant interpretations of various aspects of the content of the artwork. These questions were designed to test whether participants had made any connections with the work at the level of meaning. Participants sat inside the installation space while they answered these questions and could interact further with the work if they wished to illustrate their answers. The audio of these interviews was recorded.

During the third phase, participants filled out a written survey based on the play framework. Participants rated each of the thirteen play categories on a five-point scale from “didn't enjoy" to "enjoyed a lot". The five evaluation sessions with the general public recruited from the museum ended here, as this was the maximum time that we felt we could reasonably expect them to commit to. The fourth and final phase of the evaluation was, therefore, only completed by the invited participants (ten of the evaluation sessions). In this phase we asked participants to explain each of the answers that they gave in their survey. Those participants who were classed as "repeat" were also then asked to describe the difference between their experience of this artwork and their experience of the prototype.

\section{Analysis}

The data from the observation sessions was compiled into a spreadsheet and common interaction patterns were noted. 
This data was then compared with similar information from the evaluation sessions. The written survey data from the evaluations was then collated in a spreadsheet and ranked to produce a list of the five play categories that were most enjoyed by the twenty-two participants. In order to be able to compare this data to the first case study a similar scale was used, with the "enjoyed a lot" answers being given a value of 2 and the "enjoyed" answers being given a value of 1 . The overall rankings and particularly the answers of the repeat participants were then compared with the results from the survey in the prototype case study. The experience videos were logged and any verbal data was transcribed. This data was initially also compiled in a spreadsheet. A table summarising each experience was then produced and common patterns were analysed. This analysis focused on the timing of various actions, such as when participants first mixed or how long they read the poster. It also recorded the patterns of interaction with the various levels of the work and the patterns of turn-taking amongst pairs. Finally, the audio from the interviews was transcribed and this data along with the experience video data was coded using the audio-visual analysis software Transana (http://www.transana.org).

\section{CASE STUDY RESULTS}

In general, the evaluation participants spent much longer interacting with Just a Bit of Spin than they had with the prototype version of this artwork in the first case study. While in the first case study the duration of experiences had ranged between 2-5 minutes, the experiences for this second case study ranged between 5-20 minutes. The increased complexity of this version of Just a Bit of Spin seemed, therefore, to give people much more to play with. Participants' experience of this work was most commonly described with the word "fun" (13/22). People described the work as being fun to "play around with", said that they "had a laugh" interacting with it and that they "had some fun". They found the images "fun to look at", had fun mixing up the images and words and had fun learning how to change levels. They also had fun collaborating with their partner to work it out. These results strengthen the general impression that the artwork was quite successful as a playful interface.

The results from the pleasure survey revealed an increase in the amount of pleasure that participants registered for difficulty and competition. The data from the interviews indicated that this increase was a result of the increased complexity in the structure of the work. With two extra levels to uncover, the work now had a more puzzle-like quality to it and working this puzzle out became a driving force of many of the experiences. Participants learned about the levels when they read the poster and, as this comment indicates, from then on the urge to find all three was usually strong:

Actually I only got halfway through the instructions and went 'oh there's three levels okay' and went back and kept playing until I got the three levels.
Knowing that there were three levels helped provide impetus for exploration. It also helped shape the length of participants' experiences by giving them the confidence to complete their experience feeling like they had discovered everything within the work. The levels also encouraged goal-driven exploration, thereby increasing opportunities for people to experience the pleasure of competition.

However, not everyone was able to achieve the goals that they set and if they did not they were less likely to experience enjoyment from competition. One couple discovered how to navigate between levels but did not understand the structural relationship between the levels, the scratching interaction and the different fruit animations. After a while this couple kept navigating to the same level and did not learn how to go anywhere else. Another couple identified a pattern of single fruit images within the first two levels they discovered. They then set themselves the goal of finding a matching pattern at the third level, which had two kinds of fruit on each screen.

Such misconceptions about the artwork suggest that there might be some problems with the clarity of the interface. Both issues also highlight the need for the artwork to have strong and consistent patterns in order for people to be able to grasp the interface in the brief time that they spend with it.

But is it reasonable or even desirable to expect this artwork to have an interface that is clear to everyone? If it did, could that reduce the possibilities for experiencing the pleasures of competition and difficulty? One participant from the general public praised the work for not being too obvious:

It is good, it does take some discovery. It is not obvious. It is good, because you are not given too much information.

And one of the expert participants enjoyed the feeling that she had not worked everything out:

It was challenging, and I didn't feel like I worked it out, so I enjoyed that a lot, and I'd probably play with it again.

These comments suggest that if the interface was clearer then perhaps these two participants would have enjoyed it less. Perhaps if you want people to experience the pleasures of difficulty and competition then you have to accept that not everyone will meet the challenges and goals that you have designed. If they could, then your difficulties would not be very challenging and your goals would not be very competitive. As with most design issues it is again a question of getting the balance right. The difficult issue, however, is to determine what the right balance is for this particular artwork.

Another reason to adjust the balance of difficulty and competition is because participants' concern about solving the puzzle seemed to work against the experiential goals of 
the artwork. One participant was so focused on working it out that he did not really listen to the sound:

I was spending a lot of time trying to work out the mechanics of what affected what, and so on, and I probably needed more time to then go "Okay, we've established this, lets now play with it and listen".

Another participant could not control the navigation and indicated that this interfered with her enjoyment of the artwork:

I wouldn't think I'd get bored with it quickly, if I was playing with it, and had an idea of where I was going.

These comments are interesting because they both make the distinction that we have discussed earlier, between the preliminary explorative stage of working out what an object can do and the next more playful stage of working out what can then be done with it. The comments suggest that the problem here might be that the challenges and goals in Just $a$ Bit of Spin occurred mainly at the surface 'working it out' level and were not integrated within the content of the work which would have put them more at the playful level of 'what can be done'. Because the puzzles within the work were all at this surface level, trying to work them out took the focus away from the work's content and, therefore, away from the work's political message. This suggests that redressing the balance of difficulty and competition should involve making the surface-level interface easier while increasing the possibilities for goals and challenges within the content of the work. Although people might still not meet all of these challenges or realise all of these goals at least in trying to do so they will be engaging with the political message of the work.

Participants' answers about the ambiguous relationship between the images and the words within the artwork did reveal some of the resonances that the artist had hoped people would interpret from the work. This question generated much discussion, however, for many participants from the non-expert group this discussion was more about their confusion about the fruit imagery than any meaning they had interpreted. A doctor from the USA expressed this common response:

I understand spin, meaning the spin of the disk and all that stuff. But what did the fruit have to do with it, and what specifically does the fruit have to do with political statements or language? It just doesn't add up to me personally.

Similarly, many in the expert group did not see any initial relationship between the fruit images and the message of the work. However, the experts did not worry about this in the same way that those in the non-expert group did. Instead, they used their knowledge of the formal structures of interactive art to come up with a formal explanation for the fruit. For a web designer the fruit "symbolised that it was going into a new stage”. For a sound designer the fruit was "a visual distraction, so you pay attention to the audio". An animator commented that he "didn't really need or feel an immediate direct relationship” but that was a positive for him because "these animations are so nice and simple and ... really beautiful and I think that's all you need in a way”. Coming up with a formal explanation for the fruit seemed, therefore, to make the experts less anxious about it. The non-experts were unable to do this and the fruit imagery left them feeling anxious and perplexed.

Another aspect that puzzled participants about the fruit imagery was that it did not seem to have a consistent pattern. One participant who worked in TV production commented that there was a quite literal connection between the hard/soft level and its fruit imagery but that there was a more philosophical one at the other levels:

And with the hard and the soft, I was probably associating that less with sort of philosophies about life ... and it was more about like you know, the soft berries compared to the harder pineapple.

This literal connection in the hard/soft level was the answer that most people gave when asked if they thought there was any relationship between the words and the images. However, there was no literal connection between the words and the images at the other two levels and the lack of consistency in this pattern clearly puzzled some people. Participants seemed to expect to find this literal connection and their focus on matching this pattern might have blinded them to the much more metaphorical connections that the other two levels had.

For some people, however, puzzling over the fruit did cause them to begin making interpretations. One expert participant, an animator, talked about the way that different fruits had certain "textures and feelings" for him and that these had added to his interpretation of the words. Another expert participant, a film editor, made a connection between the positive and negative character of the words and the fruit:

You're quickly shifting ... like that idea of ... cutting between two things ... like an angel and a devil character, like I don't know, but like in old black and white movies where they chop quickly between two things 'cause they show the darker side of something, you see the darker side of the fruit.

Other participants made more explicit connections between their interpretations of the artwork and the fruit. For example a woman who had questioned the assumptions behind the meanings of opposing words thought about “comparing apples and oranges”. Similarly, another expert participant, a film designer, connected figures of speech involving fruit with her interpretation of the work:

A bad bunch of fruits and bad politicians ... Fresh fruit, fresh ideas ... Lemon, a bit of lemon in there ... 
She, like some other participants, also saw the fruit as working in contrast to the words:

The fruit was beautiful and what they were saying was stagnant so ... For me there wasn't growth in the spin of the politicians but there was growth inside of the fruit.

There was also evidence that participants were able to creatively interpret the more metaphorical meanings that the artist had intended the fruit to convey. Four participants talked about the way the forwards pear animation symbolised growth or creation and most of these also connected the backwards pomegranate animation with disintegration. One participant, a screenwriter, also understood the connection the artist was trying to make with the mixed up banana/orange graphic:

... they're talking about something and nothing and also about re-branding and so ... for me that was really about obfuscating and confusion and so the last image being the ... orange/banana in banana skin sort of made sense ...

These comments indicate that for some people the ambiguity of the fruit imagery did work to encourage interpretative responses. That many of these people came from the expert group suggests that their ability to initially solve the fruit puzzle with a formal explanation might have given them the freedom to then play more with their interpretations. These participants did make some interesting interpretations of the fruit and because the ambiguity made it difficult to lock down the meaning of the work they were clearly more thoughtful. For some people $(8 / 22)$ this lack of interpretive closure left them feeling "frustrated", "confused" and "curious". Others (11/22) described their experience more positively as "thought provoking”, "intriguing”, "interesting”, "stimulating” and "engrossing".

\section{REFLECTION ON RESULTS}

The new three-level structure clearly provided many more opportunities for people to experience the pleasures of difficulty and competition. Working out the puzzle of these three levels, however, did not seem to make people engage more with the content of the work. These results suggest that the structure of the work needs to be redesigned so that the areas of structural difficulty are more relevant to the content. We see the success of this redesign as being tied to the concept of "meaningful play" we discussed earlier. This involves interactions being integrated within the wider context of the work. This type of integration is also important to Polaine, who argues that, as with toys, playful interactive artworks are ones where: "the challenge is not about trying to understand the interface to the work; at this point the interface is the work.” [9]

This concept is essential if one wants to create an interactive work where the understandings and/or transformations that the work generates emerge primarily from the participant's interactive experience rather than from some concept that they might have read about in the artwork's descriptive signage. The difficult question, then, is how one designs for the pleasures of difficulty and competition in such a way that that their challenges and goals are integrated and, therefore, meaningful within the context of the work.

Rozendaal et al. make a distinction between goals that "emerge from an activity" and goals that are "imposed upon an activity" [10]. They link goals that emerge during interaction to the creative and improvisational behaviour of the participant. Although such goals might be suggested by the properties and character of the interactive system, the participant plays a major role in creating them at the moment of interaction. Imposed goals, on the other hand, are those directed by the system itself and these are regarded as requiring focus and perseverance from the participant. Given the character of these two types of goals one might predict that creative emergent goals would be more associated with play. Rozendaal et al.'s study, however, found that the playful engagement of participants with a simple game increased when they were given goaldirected tasks [10]. In their study it was rare for participants to create their own goals.

As Rozendaal et al.'s study participants were all adult, it could be argued that this was a consequence of the preference that other studies have shown adults have for structured rather than improvisational play [5]. It could, however, also be argued that this was a consequence of the game design itself, which in its simplicity might not have opened up much space for creative goal development. The results that we have seen in our study here and in the first case study suggest that the existence of a space for creative goal development hinges on both factors. The character of the participant plays a role, in that they need to be playful and to make a personal connection with an interactive work before they will begin creating goals. The character of the artwork also plays a role and some types of works were observed to be more open to goal creation than others. Works like this second version of Just a Bit of Spin were more strongly goal directed and for adult participants this led them to frequently focus intently on these systemdirected goals alone. The prototype version of Just a Bit of Spin did not have such clear goals and this did lead some participants to create their own goals.

A common feature of all of the directed goals both in my works and in the games created for Rozendaal et al.'s study was that these goals were given outside the context of the work, either verbally or through signage. While this is a usual, and for more complex games a necessary, practice it might be that for the short audience participation times in a gallery context it would be preferable to keep such instructive goals to a minimum. In this second case study, participants were very focused on understanding and following these goals. Perhaps if a participant's first focus is on understanding the goals of another then play will not 
occur until these goals have been understood. Many adult participants, however, seem to like having goals to spark them off and to provide constraints for their behaviour. Finessing this relationship between directed and emergent goals, then, is a question of finding the right balance for the work in question and the type of audience evaluation carried out in this study can help to do this.

The results of this study also suggested that both patterns and ambiguity within an interactive artwork can evoke playful behaviour because both give participants something to work out or puzzle over. Having this similar puzzle-like quality means that patterns and ambiguity can stimulate the playful pleasures of difficulty and competition. However, with one operating on a principle of consistency and the other operating on a principle of inconsistency, patterns and ambiguity each have a different relationship to these two pleasures. Their different characters also mean that patterns and ambiguity do not always sit easily together.

The ambiguity in the second version of Just a Bit of Spin aimed to increase opportunities for participants to play with interpretation but it also sometimes seemed to work against the pleasures of play by challenging participants' strong desire to seek out and uncover consistent patterns. As one participant explained, her confusion over the fruit in Just a Bit of Spin worked against her desire to:

... see things that match, and things that are symmetrical, and for them to make sense, and for there to be a story ...

Ambiguity, with the multiple interpretation possibilities it offers, necessarily makes it harder for an audience to lock down patterns. This makes it more difficult for them to experience the pleasure of knowing they have solved a puzzle and, therefore, reduces the possibility that they could feel the competitive pleasure of having achieved a goal or feel the pleasure of having overcome a difficulty. If participants are particularly focused on pattern recognition, ambiguity could easily be associated more with displeasure than pleasure.

In this study, however, there were a group of participants who did gain pleasure from ambiguity. This group did so only after they felt they had worked out the pattern of the fruit. Their minds then stopped being focused on the goal oriented challenges of pattern recognition and they became more open and playful in their exploration of the meanings within the work. Working out the patterns of the fruit seemed to create a rigid structure that they could then play within. This process also, perhaps, provided that feeling of safety or a protective frame that is necessary before play can begin.

Something similar to this feeling of safety is described by Sengers and Gaver, who note how important it is for systems that are ambiguously open to interpretation to give people "a license to reinterpret the system's behavior and its relationship to them" [12]. Giving people something that will provide them with such a licence is perhaps even more important in an interactive art context, where people often approach each artwork expecting there to be a single correct interpretation.

In the second case study, the group of people who had this sense of having a licence to reinterpret the fruit images within the artwork were those who felt that they had solved the puzzle of its structural purpose. This group were all experts and, although the purposes they proposed differed, each purpose related to the expertise of the person who proposed it. Perhaps this personal interpretation gave these experts a feeling of ownership over their interpretation and this then resulted in this group of participants adopting a more conversational relationship to the artwork and playfully interrogating it further. As with Sengers and Gaver's approach above, this suggests that what is at issue here is the type of relationship that exists between audience and artwork and the status that each has within this exchange. For the expert participants in the second case study this was a relationship of expert to expert and this made their interactions more conversational. Conversely, the other participants seemed to adopt the role of a novice waiting to be taught something by an expert artwork and this made their interactions less conversational.

The process of pattern recognition can also be viewed in this way but it is a process that involves a different, perhaps less dynamic, conversational relationship. In interactive artworks this relationship usually involves repetitive interrogative processes of action and response and is, therefore, often less about an exchange of ideas and more about investigative interpretation. The main pleasure in this comes when one finally recognises a pattern and feels like one has reached a state of mutual understanding with the artwork, a state where both parties are speaking the same language. The key pleasures of the experience of pattern recognition, therefore, relate to the reaching of this final destination and are those of meeting the challenge of difficulty and of achieving a competitive goal.

The process of interpreting ambiguity, on the other hand, remains open-ended and does not have such a sense of final achievement. Its pleasures, then, relate more to the pleasures of the journey and so discovery and exploration become a more important part of this experience. Interpreting ambiguity can also, as we have seen, be a creative act and it is because ambiguity also evokes the pleasure of creation that it can be such a powerful strategy for evoking play. This creative interpretation will not occur unless the audience feels that there is space or licence for them to act in this way and this feeling is contingent upon the relationship set up between artwork and audience. The character of this audience and in particular their expertise in the world of interactive art can help to develop such a relationship. If, however, one wants to achieve this with a wider audience, the artwork system will also need to be involved in developing this relationship. 
As strategies, both patterns and ambiguity are useful for designing for play within an interactive art context. Designing with patterns is, in some ways, the easier strategy to implement, in part, because it makes use of the universal human drive towards pattern recognition. The type of pleasures that this experience evokes also satisfy the preference we know adult audiences have for play to be more rule-based. Designing with ambiguity, although more difficult to achieve successfully, can, however, result in more intense playful pleasures. This is because of the creative and improvisational nature of the play behaviour it produces. For an adult audience this type of play is often unusual and, therefore, more exciting. Working with patterns and ambiguity together, enables one to create a rhythmic relationship between the safe world of rule-based play and the headier world of improvisational play or, in other words, between directing the play experience and providing opportunities for play to emerge through the creative activities of the player. However, it is important to remember that in trying to create the beat and tempo of these rhythms the idea is not that the artist is the composer and the audience is the listener. Rather, both artist and audience are musicians and the design needs to provide opportunities for them to jam together.

\section{REFERENCES}

1. Caillois, R. Man, Play, and Games. Thames and Hudson, UK, 1962.

2. Costello, B. A Pleasure Framework. Leonardo, 40 (4). 370-371.

3. Costello, B. and Edmonds, E., 'A Study in Play, Pleasure and Interaction Design.’ in Designing Pleasurable Products and Interfaces, (University of Art and Design Helsinki, 2007), ACM, 76-91.

4. Groos, K. The Play of Animals. D.Appleton and Company, New York, 1898.
5. Guitard, P., Ferland, F. and Dutil, E. 'Toward a Better Understanding of Playfulness in Adults.' OTJR:

Occupation, Participation and Health, 25 (1). 9-22.

6. Huizinga, J. Homo Ludens: A study of the play element in culture. Beacon Press, Boston, MA., 1955.

7. Hutt, C. Exploration and Play in Children. in Sutton Smith, B. and Herron, R.E. eds. Child's Play, Robert E. Krieger Publishing, Florida, 1985, 231-250.

8. Lieberman, J.N. Playfulness: Its Relationship to Imagination and Creativity. Academic Press, New York, 1977.

9. Polaine, A. 'An Invitation to Play.' Askham, G., Clements, L., Catlow, R., Garrett, M. and Morgana, C. eds. Game/Play Exhibition Catalogue, QUAD Publishing, UK, 2006, 18-19.

10.Rozendaal, M., Reyson, D. and De Ridder, H., 'Product Behavior and Appearance: Effects on experience and engagement during experiential and goal directed tasks.' in Designing Pleasurable Products and Interfaces 2007, (University of Art and Design Helsinki, 2007), ACM, 181-193.

11.Salen, K. and Zimmerman, E. Rules of Play: Game Design Fundamentals. MIT Press, Cambridge, MA., 2004.

12.Sengers, P. \& Gaver, B. 2006, 'Staying Open to Interpretation: Engaging Multiple Meanings in Design and Evaluation', Proceedings of Designing Interactive Systems: DIS 2006, 26-28 June, University Park, Pennsylvania, USA, ACM, pp. 99-108.

13.Wright, P. C. \& McCarthy, J. 2005, 'The Value of the Novel in Designing for Experience', in Future Interaction Design, A. Pirhonen, H. Isomaki, C. Roast \& P. Saariluoma (eds.), Springer Verlag, London, pp. 930. 